\title{
ORACIONES FINALES EN HEBREO RABÍNICO
}

\author{
MIGUEL PÉREZ FERNÁNDEZ \\ Universidad de Granada
}

1. Me circunscribo al llamado hebreo rabínico 1 (HR) o hebreo tannaítico, que se refiere al hebreo aún hablado en Palestina hasta mediados del s. III d. C., reflejado con toda seguridad en un corpus formado por Mišna, Tosefta’, Midraším halákicos y Seder 'Olam Rabbah'.

2. Como punto de partida, veamos el interesante texto de Sanh $4,5^{2}:$

Por esto fue creado el hombre "único» en el mundo:

a) Para enseñar (lé-lammed) que todo el que destruyere una sola vida, se le cuenta como si hubiera destruido el mundo entero; y todo el que mantiene una sola vida, se le cuenta como si hubiera mantenido al mundo entero.

' Cf. M. BAR-Asher, "L'hébreu mishnique; esquisse d'une description", Académie des Inscriptions \& Belles-Lettres, Comptes rendus 1990, 200.

Uso las siglas habituales en Biblioteca Midrásica para los textos mísnicos y midrásicos. Además $K$ : Ms. Kaufmann de la Mišna, edición facsímil de G. BAER, (reimpr. Jerusalén 1969); $H$ : edición crítica del Midrás Sifre Números (SNm) por H. S. HoRovitz (reimp. Jerusalén 1966); F: edición crítica del Midrás Sifre Deuteronomio $(S D t)$ por L. Finkelstein (reimp. Nueva York 1969); $L$ : edición crítica de Mekilta de R. Yismael (Me̋k) por J. Z. LAUTERBACH (Filadelfia 1976); W: edición de Sifra por J. H. Weiss (Viena 1862).

${ }^{2}$ Traduzco del texto de $K$. Las diferencias con el textus receptus (cf. edición de Albeck-Yalon) no afectan aquí al aspecto gramatical que nos ocupa. Pero es significativa la especificación/limitación en Albeck-Yalon de que la vida que se ha de conservar o destruir sea "de Israel", así como la supresión del título divino "el Rey de reyes de reyes". Sobre el sentido y teología del "único" (yahild), cf. M. PÉREZ FernándeZ, «El numeral heis en Pablo como título cristológico: Rom 5,12-19; Gal 3,20; cfr. Rom 9,10", Estudios Biblicos 4 (1983) 325-340; IDEM “Versiones targúmicas de Génesis 3,22-24", Simposio Biblico Español, Madrid 1984, págs. 457-475. 
b) Y en razón de la paz social, para que nadie pueda decir (še-lo' yo'mar) a su prójimo: "mi padre es más ilustre que el tuyo".

c) Y para que no continúen (še-lo’ yěhû) los herejes diciendo: "hay muchos poderes en el cielo".

d) Y para proclamar (lé-haggîd) la grandeza del Rey de reyes de reyes, el Santo, bendito sea. Pues el hombre acuña cien ${ }^{3}$ monedas con un mismo sello y todas se asemejan unas a otras; pero el Rey de reyes de reyes, el Santo, bendito sea, ha acuñado a todo hombre con el sello del primer hombro y ninguno se parece a su prójimo. Por esto todos y cada uno de ellos están obligados a decir: "por mí ha sido creado el mundo".

e) Y no sea que os atreváis a decir (šemma’ to'měrû): “¿qué tenemos nosotros que ver con tal problema?", ¿no es verdad que ya está dicho: «si el testigo, lo haya visto u oído, [no lo denuncia, incurre en falta]?» [Lev 5,1].

f) Y no sea que os atreváis a decir (ร̌emma’ to’měrû): “¿Qué responsabilidad tenemos nosotros en la sangre de éste?", ¿no es verdad que ya está dicho: "cuando los perversos perecen se alboroza la ciudad?" [Prov 11,10].

Seis oraciones finales explican el porqué de la creación del hombre "único»; éstas son sus formas:

a) y d): $l e x-+$ infinitivo.

b) y c): $s e-l o^{2}+$ imperfecto.

b) y c): semma’+ imperfecto.

3. Además de estos tres modos, HR conoce las siguientes formas de construir una oración final:

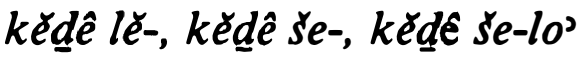

bisbil se-, bisbil se-lo'

'al měnat lè-, 'al měnat se-

Quedan fuera de uso en HR las formas bíblicas con lë-macan, lexmacan 'aser, ba'abûr, ba'abûr 'ašer, pen ${ }^{4}$. Las oraciones finales bíblicas construidas con 'ašer y 'ašer $10^{\prime}+$ imperfecto tienen un calco en

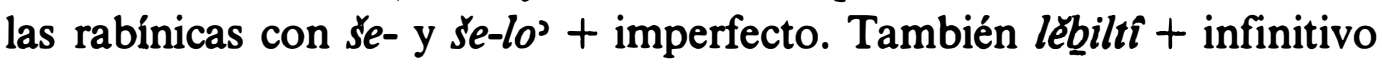
desaparece sustituido por $\zeta^{\zeta} e-l o^{\prime} l \ell^{\prime}$ -

El modo elegante en hebreo bíblico de expresar la finalidad

${ }^{3}$ Textus receptus: «muchas».

4 Cf. M. H. Segal, A Grammar of Mishnaic Hebrew, Oxford 1927, \&\& 302-303; R. MeYer, Gramótica de la Lengua Hebrea, Barcelona 1989, 8 117,2. 
mediante la coordinación de oraciones con waw (es frecuente la secuencia: imperativo + wayiqtol/wĕ-qatal) ${ }^{5}$ se da también en HR, como en 'A

Considera tres cosas para no caer (wě 'ên 'attâ $\left.b a^{3}\right)^{6}$ en manos del pecado.

Pero suprimida o abandonada en HR la conversión de tiempos, los rabinos recurren cada vez menos a la coordinación en favor del infinitivo con $l-$ y las conjunciones propias. En este artículo expondré el uso final del infinitivo y de las conjunciones še-, bišbîl, kĕdê $y$ šemma' ?.

4. $l-+$ infinitivo.

Sólo el infinitivo constructo ha quedado en uso en HR, y siempre con $l$ - antepuesto, de forma que $l$ - + infinitivo es última forma que ya no puede ser ulteriormente descompuesta. A este conjunto se antepondrá la negación še-lo’ y cualquier preposición, como en 'Erûb 2,6:

'asûr mi-lě-haknnis u-mi-lé-hôŝ̀' lô (le está prohibido introducir o sacar nada).

El valor final de este infinitivo es usual y no hará falta multiplicar los ejemplos ${ }^{8}$ :

Se juntaron todas, unas con otras, para tomar consejo (li-tôl cesâ. [SNm 133,1 ( $\begin{array}{ll}H & 176)] \text {. }\end{array}$

Las muchachas de Jerusalén salían con adornos blancos tomados en préstamo para no ofender ( $\left(Y e-l 0^{\circ}\right.$ lé-bayyes) a quienes no los tenían. [Tac $a$ 4,8].

De especial importancia son en los midrasion tannaíticos los llamados infinitivos exegéticos con los que se inicia abruptamente la explicación de una cita bíblica. Entre los más usuales son: lę-habî $\hat{\imath}^{2}$,

${ }^{5}$ Cf. R. MEYeR, op. cit., \& 17,1.

6 En las ediciones impresas se lee 'q 'attá, pero $K$ lee 'ên 'atta.

7 Cf. M. H. Segal, op. cit., $\$ \$$ 514-515.

${ }^{8}$ Para el hebreo bíblico, cf. R. Meyer, op. cit., \& 102,4a. 
lë-hôs $\hat{\imath}$ ", lë-hôdîia lë-lammed, cuyo sentido es "[esto se dice] para incluir / excluir / dar a conocer / enseñar...». Pueden considerarse respuesta a una pregunta implícita del tipo lamma’ ne'emar. Ofrezco dos ejemplos suficientemente expresivos:

"Cuando un hombre se acalore contra su prójimo para matarlo" [Ex 21,14] ... [Dice] "cuando se acalore», para excluir (lë-hôs si) al que actúa por inadvertencia. [Dice] "un hombre", para excluir (léhôsî̀) al menor de edad. [Dice] "un hombre», para incluir (lě-habî') a los extraños. [Dice] "contra su prójimo", para incluir (lé-habhi) al menor de edad. [Dice] "contra su prójimo", para excluir (lë-hôs $\hat{\imath} \hat{\imath}^{\text {”) a }}$ los extraños. [Měk a Ex 21,14 (L III 36-37)].

"Hízolo así Aarón" [Num 8,3]. [Esto se dice] para proclamar (lěhốdiac) la alabanza de Aarón, que actuó como Moisés le había ordenado. [SNm 60,1 (H 57)].

5. Se- final y exegético 9 .

$\zeta$ Se- no es abreviación o evolución de sašer. Está presente en el estrato semítico más antiguo, y en la Biblia aparece cinco veces en textos tan primitivos como Jue 5-8, y una vez en Reyes y Job. Probablemente, porque tal forma se consideró un vulgarismo del Norte, desapareció del hebreo literario bíblico hasta volver a entrar en la última época bíblica (Cant, Ecl, Sal, Jon, Lam), donde se alterna con 'ašer ${ }^{10}$.

En Ecl 3,14 aparece un še-final/consecutivo, muestra de la transición al HR:

Dios actúa para que se le tema (še-yirể mi-lë-fanayw).

Efectivamente, en HR $\breve{s e}-+$ imperfecto puede expresar el sentido final o última intención de una acción. $\mathrm{Y}$ es en la exégesis donde también se usa abruptamente tras una cita bíblica para expresar el sentido o intención de dicha cita (cumple así la misma función que los infinitivos exegéticos de los que ya hemos hablado). Baste un solo ejemplo de $S N m$ 21,3 (H 24):

"Quedará limpio de pecado" [Num 5,31]. [Esto se dice] para que

\footnotetext{
9 Cf. K. AlbreChT, "Še- in der Mischnah», ZAW 31 (1911) 205-217.

10 Cf. E. Y. KuTsCher, A History of the Hebrew Language, Jerusalén 1984, $\$ 45$.
} 
nadie tenga que decir ( $\breve{e}$-lo’ yo’mar): ¡Ay de mí, que maté a una hija de Israel!

\section{Bišbill še-.}

Es una conjunción propia del HR. Literalmente: «en la senda de que» el sentido es causal o final, "por causa de que» o "para que», ambos valores en ocasiones confundibles cuando porque = para que. Pero cabe notar una constante en su uso:

a) En construcciones con participio o nominales, el sentido es propiamente causal. Así en $S D t 3$ ( $F$ 11):

Bišbil še-ha-melek kašer ... bišbil še-’ên lô koah lè-haknîsenû la'ares, (porque el rey es muy capaz ... porque carece de fuerza para hacernos entrar en el país).

b) Con imperfecto expresa una causalidad final, por lo que debe interpretarse las más de las veces como simple conjunción final: "para", "para que», "a fin de que». Así en Dem 3,3:

Y si desde el principio recoge [los frutos] para que no se estropeen (bisbll se-lo' yo’bědû).

En $R H$ 2,6 advertimos la equivalencia entre bišbil še- y kĕdê še-:

No porque tuvieran necesidad de los testigos, sino para que no se marcharan (kédê se- lo' yese'u) " defraudados y para que se acostumbraran (bisbil še-yèhü rëgillm) a venir.

7. Këdê še-, kẹdê lè-.

La diferencia entre el uso del imperfecto ( $k e \check{d} \hat{e}$ še-) y el del

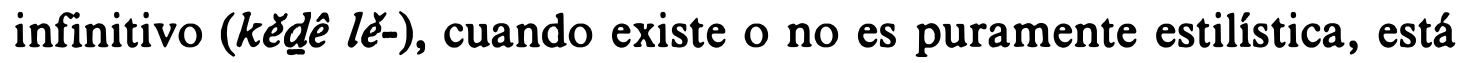
en el modo más subjetivo, personal y persuasivo del imperfecto, frente al más impersonal del infinitivo ${ }^{12}$. No siempre acertamos a mostrar en castellano la diferencia de matiz, pero puede compararse Bër 1,1 (una normativa rabínica "para alejar -kédê lë-harhiqq- al hombre del pecado"), con Berr 2,2 (la recomendación de que la normativa "no es sino para que uno consienta en aceptar -kédê se-

\footnotetext{
"Pero $K$ lee sólo se-lo', sin këdê (cf. infra).

12 Cf. M. Mishor, The Tense System in Tannaitic Hebrew, Tesis Doctoral, Universidad Hebrea de Jerusalén 1983.
} 
yĕqabbel calayw - el yugo del reino de los cielos»). Pero en ambos textos (Bĕr 1,1 y 2,2$) K$ lee 'ellla' lë-harhîq y 'ellla' yĕqabbel respectivamente. El uso generalizado de këdê para introducir una simple oración final podría pertenecer a un estadio más tardío del HR.

Lo propio de esta partícula, en virtud de su vis etymologica, ké+ day: "como bastante", "como suficiente», es introducir una oración atributiva o adjetiva para determinar un nombre. Se expresa así no la intencionalidad final de un sujeto externo, sino algo de la finalidad/naturaleza de la cosa misma. En Šabb 8 se concentran numerosos ejemplos de este kĕdê lĕ- con el que se expresa el valor cuantita-

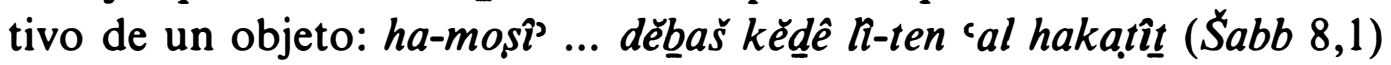
no se refiere al que transporta miel para ponerla sobre la herida, sino a "quien transporta tal cantidad de miel como para poner sobre una herida»; de la misma manera, šemen kĕdê la-sûk 'eber qatan es "aceite como para ungir un pequeño miembro" (ibid.), y hebel kĕdê la-'asôt 'ozen es "cuerda de tamaño como para hacer un asa", y nëyar kědề li-ḱtôb calayw qešer mûkěsîm es "papel de tamaño como para escribir en él la nota de los recaudadores" (Šabb 8,2), y děyyô kédê li-k̂tôb šĕtê 'ôtiyôt es "tinta en cantidad tal como para escribir dos letras" (Sabb 8,3). Advertir el valor adjetival de estas oraciones finales es decisivo para no transformarlas en oraciones que expresen la intención final del sujeto.

En todos los ejemplos que he podido controlar kĕdê funciona de hecho como un adjetivo indeclinable, "suficiente", "bastante", que puede introducir tanto un infinitivo con $l \dot{l}$ - como el sustantivo verbal correspondiente. En Hull 11,2 encontramos que a la pregunta "¿Cuánta lana hay que darle?», se responde: "cuanta suficiente para

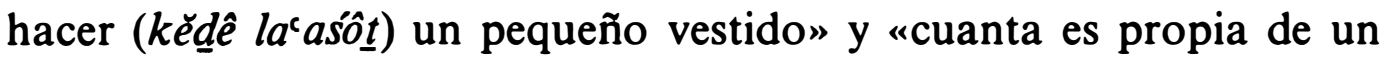
regalo (kédê mattanâ)»; en ambos casos lo que se expresa no es la finalidad para la que se quiere la lana, sino la cantidad de lana que se quiere.

\section{8. Šmma .}

Procede muy probablemente de še- + lě- $+m a ̂$. Un estadio intermedio lo encontramos en hebreo bíblico tardío (Cant 1,7: “¿Por qué - ša-lammâ- habré de ir errante?»). Existe el calco arameo dilěma $a^{2}$, acaso proveniente del mismo HR. En todo caso la terminación en 'alef es de influencia aramea. En $K$ encontramos la vocalización semmes. 



conjunción, "no sea que", "para que no". A la conjunción še-lo" añade el matiz de temor e inseguridad. Sustituye el bíblico pen, como es claro en $S D t 43$ ( $F 92$ ), donde la frase bíblica "cuidad que no (pen) se engañe vuestro corazón" (Dt 11,6) es traducida en "cuidad de no (̌̌emma) rebelaros contra el Omnipresente».

Es muy típico del HR el uso de šmma para justificar un texto bíblico. La fórmula ya estandarizada en los midrasimm tannaíticos es semma' to'mar/to'mérû... talmûd lomar, "No sea que interpretes / para que no interpretes / para que no puedas decir..., es por lo que el texto bíblico dice»; justamente la razón del texto bíblico es evitar esa posible y errada interpretación. Esta fórmula es muy frecuente en $S D t$ y $S i f r a{ }^{2}$, muy rara en Mĕk y está ausente en $S N m$. También se encuentra con variantes en Mišnâ: en Sanh 4,5, texto con que hemos abierto este artículo (fórmulas e y f), la razón de la cita (halo këbar ne'emar?) de Lev 5,1 y Prov 11,10 es que nadie pueda sacar (̌̌emma' to'mĕrû) consecuencias de insolidaridad.

Terminemos con un precioso texto sobre la paz anhelada en la tierra prometida:

Para que no podáis decir (̌̌emma to’měrû): «hay alimento y comida, pero no habiendo paz es como si nada", es por lo que el texto dice (talmúd lomar): “Pondré paz en el país" [Lev 26,6]. [Sifra” a Lev 26,6 (W 111a)].

\section{RESUMEN}

Dentro del Corpus Tannaiticum y tomando como punto de partida el texto de Sanh 4,5, se estudian distintos tipos de oración final: lě- + infinitivo, se- con valor final y exegético, el uso de bišbil se- en oraciones nominales y verbales, valor y uso de kédê lè- y kédê se-, y origen y uso de semma’.

\section{SUMMARY}

Within the Corpus Tannaiticum and taking as a point of departure the text of

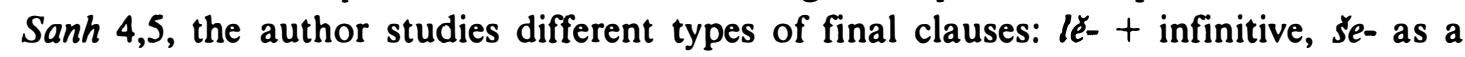
final and exegetical particle, the use of bisbil se- in nominal and verbal clauses, the



